\title{
JUÍZES, MOLEIROS E CONSTITUIÇÃO
}

JUDGES, MILLERS AND CONSTITUTION

Wagner Vinícius de Oliveira*

\section{RESUMO}

Esse artigo desenvolve uma perspectiva crítica sobre as instituições judiciais. A problemática consiste em questionar se a existência de juízas e juízes protege adequadamente os interesses individuais, considerase inviável equiparar de maneira direta e necessária existência judicial e proteção individual. Para tanto, elege-se a revisão bibliográfica enquanto meio para fornecer dados para destacar alguns aspectos de ordem normativa e de composição institucional do Judiciário brasileiro. Portanto, a concepção de constituição radical é condição necessária, mas insuficiente para a compreensão dos fenômenos analisados. Os resultados obtidos com a realização da pesquisa sugerem a superação da desconfiança em relação a atuação social, contudo verificam-se dificuldades de constatação e operacionalização da participação social efetiva. Conclui-se pela impossibilidade de associar a existência de juízas e juízes à proteção de direitos e de garantias fundamentais; novamente, necessários, porém insuficientes.

Palavras-chave: Estado democrático de direito; Instituições; Judiciário brasileiro; Participação social.

\section{ABSTRACT}

This article develops a critical perspective about the judicial institutions. The problematic is to question whether the existence of judges adequately protects individual interests, considers that it is not feasible to equate direct and necessary the judicial existence the individual protection. To this end, it chooses the bibliographic review as a means to provide data to highlight some aspects of a normative order and of the institutional composition of the Brazilian Judiciary. Therefore, the concept of radical constitution is a necessary condition, but insufficient to understand the analyzed phenomena. The results obtained with the research suggest overcoming distrust in relation to social performance; however, there are difficulties in finding and operationalizing effective social participation. It is concluded that it is impossible to associate the existence of judges with the protection of fundamental rights and guarantees; again necessary but insufficient.

Keywords: Democratic State of law; Institutions; Brazilian Judiciary; Social participation.

* Doutorando em Direito pela Universidade Federal do Rio de Janeiro.

Mestre em Direito pela Universidade Federal de Uberlândia. Advogado. oliveirawagnervinicius@gmail.com 
INTRODUÇÃO; 1 POVO, CONSTITUIÇÃO E INSTITUIÇÕES JUDICIAIS; 2 AINDA HÁ JUÍZES EM BERLIM, MAS TAMBÉM EXISTE O POVO; 3 ENQUANTO ISSO... UMA VERSÃO ABRASILEIRADA; 4 TENSÕES ENTRE CONSTITUCIONALISMO E DEMOCRACIA: UMA RESPOSTA OFERECIDA PELA CONSTITUIÇÃO RADICAL; CONCLUSÃO; REFERÊNCIAS.

\section{- INTRODUÇÃO}

Toma-se como motivação inicial o clássico poema de François Andriex, "O moleiro de Sans-souci", 1 cuja principal ideia consiste na afirmação de que "ainda há juízes em Berlim". Isso é, dobram-se as apostas na promessa de que o Judiciário, na salvaguarda da sociedade, atue de modo imparcial para conter os abusos inclusive do próprio Estado. Esse tipo de crença é procedente apenas em parte, pois não há como generalizar essa expectativa de comportamento institucional em relação a toda e qualquer atuação judicial. No mesmo sentido, não há como classificar alguns gestos isolados e voluntaristas de determinadas magistradas e magistrados como se fossem capazes de representar o posicionamento do Judiciário brasileiro.

Embora o recurso ao poema pudesse ter sido descartado, porque já bastando utilizado, cumpre o objetivo de retomar o debate sobre a relevância das participações sociais. A linha mestra que será desenvolvida nesse artigo consiste na afirmação de que ainda há juízas e juízes, mas algumas e alguns se comportam como se o povo não existisse, portanto é necessário que o povo participe das decisões relevantes para a coletividade.

Muito já se escreveu sobre esse poema e sobre o Judiciário brasileiro, porém, dessa vez, a tônica recai sobre a questão problema de que havendo juízas e juízes automaticamente os interesses individuais estariam resguardados. A hipótese testada consiste em destacar alguns aspectos de ordem normativa e de composição institucional do Judiciário brasileiro que tornam inviável equiparar de maneira direta e necessária existência judicial a proteção individual e procuram fundamentar as inferências realizadas.

Para delimitar a quantidade e a abrangência das temáticas relacionadas a variável povo, utiliza-se esse substantivo abstrato num sentido bastante próximo as ideias de JeanJacques Rousseau, ${ }^{2}$ enquanto fonte primária de soberania, manifestada por intermédio da vontade geral - que não se confunde com a soma das vontades individuais. Diferente de população, porque se desenvolve mediante determinado vínculo jurídico político (cidadania), distinto de Estado-nação, porque não circunscrito ao mito fundacional comum (natio) ou representativo da soberania nacional, enquanto titular do poder constituinte originário, aos moldes de Emmanuel Joseph Sieyès. ${ }^{3}$

\footnotetext{
1 Trata-se do poema: Le meunier Sans-souci de François Guillaume Jean Stanislas Andriex (1759-1833). Cf. ANDRIEUX, François. Le meunier de Sans-souci [Anecdote]. Paris : Bibliothèque Numérique Wikisource, [s.d.] (Livre électronique).

${ }^{2}$ Cf. ROUSSEAU, Jean-Jacques. Du contrat social ou principes du droit politique. Paris : Union Générale d’Éditions, 1963.

${ }^{3}$ Cf. SIEYÈS, Emmanuel Joseph. Qu'est-ce que le Tiers Etat?. Paris : Editions du Boucher, 2002.
} 
O objetivo central consiste em delinear parcela das dificuldades estabelecidas entre as administradoras e os administradores temporários da "justiça" institucionalizada e o conjunto de suas destinatárias e destinatários. Considerações críticas serão endereçadas às instituições judiciais, não necessariamente a suas membras e membros. Certo é que coincidências podem ocorrer. No entanto, desferir críticas as instituições judiciais, não significa o endosso irrestrito a todas as crenças ou vontades supostamente populares.

As instituições judiciais gozam de uma rede de proteção jurídica e política constituída pelas garantias e vedações dispostas no próprio texto da Constituição da República Federativa do Brasil de 1988 (CRFB/88) e na Lei Orgânica da Magistratura Nacional - Lei complementar n. $35 / 1979$, por exemplo. Quanto à seara política, tem-se a insistente ideia de insindicabilidade das decisões judiciais, especialmente quanto ao afastamento de eventual controle social.

Dentre outros fatores, essas garantias institucionais podem representar o convite para uma atuação imoderada de parcela significativa das magistradas e magistrados brasileiros. Por sua vez, influencia o modo como algumas magistradas e magistrados concebem e desempenham suas funções contrariamente aos valores democráticos e republicanos. Isso sugere de modo significativo e aprofundado o viés explicativo da baixa representatividade de pautas e pensamentos não hegemônicos no Judiciário brasileiro.

Além disso, busca-se testar e construir argumentos no sentido de fortalecer o ponto de vista de uma interação necessária entre várias e vários partícipes, coautores e coautoras, igualmente corresponsáveis pela realização das promessas constitucionais delineadas em outubro de 1988, valendo-se do conceito de constituição radical. ${ }^{4}$ Para tanto, elege-se a revisão bibliográfica em livros, artigos de revista especializadas nacionais e estrangeiros e de dados atualizados sobre o "perfil sociodemográfico dos magistrados brasileiros", 5 como meio ou etapa na pesquisa para a construção de uma resposta à temática examinada.

Cabe registrar que teorias, geralmente estrangeiras, salpicadas de alguns casos práticos emblemáticos, podem perfeitamente apresentarem-se como metodologias deficitárias à medida que se encontram dificuldades para mensurar o grau de verossimilhança com as práticas jurisdicionais brasileiras. No mais das vezes, a análise pura e simples de decisões judiciais produz um diagnóstico insuficiente e, portanto, insatisfatório. Propõe-se, assim, articular subsídios acerca da composição social da magistratura nacional e suas eventuais implicações no processo de exclusão do povo, para fundamentar a conclusão de uma participação democrática mais efetiva sob as bases da constituição radical.

Apresentado o contexto, passa-se à exposição da trajetória em que esse artigo se desenvolve, ressalvadas essa parte introdutória, a conclusão e as referências, as reflexões serão apresentadas em quatro tópicos sequenciais. Primeiro, detalham-se os possíveis relacionamentos estabelecidos entre povos e constituições, com a finalidade de se compreender que historicamente existe uma oposição em relação às participações sociais. Em seguida, complementa-se a existência da "justiça" institucionalizada com as participações sociais de acordo com o recorte proposto. A contextualização das dificuldades normativas e institucionais serão realizadas no terceiro tópico.

\footnotetext{
${ }^{4}$ Cf. CHUEIRI, Vera Karam de. Constituição radical: uma ideia uma prática. Revista da Faculdade de Direito (UFPR), Curitiba, n. 58, 2013, p. 25-36.

${ }^{5}$ Cf. BRASIL. Conselho Nacional de Justiça. Perfil sociodemográfico dos magistrados brasileiros 2018. Brasília, 2018.
} 
Por fim, no quarto tópico, são examinadas algumas das tensões entre constitucionalismo e democracia, contrastada com a proposta oferecida pela constituição radical. Logo, uma das contribuições desse artigo consiste no reforço para a possível superação da confiança exagerada em relação a atuação do Judiciário brasileiro, ao mesmo tempo em que se suspeita das participações sociais para contribuir com o desenvolvimento sobre as questões constitucionais.

\section{POVO, CONSTITUIÇÃO E INSTITUIÇÕES JUDICIAIS}

Pluralidade e disputa de ideias são perspectivas que sustentam as manifestações públicas dos compromissos identitários dos distintos grupos e pensamentos que compõem o povo. Esse intrincado elemento social - inapreensível por qualquer tentativa de definição peremptória - que mescla aspectos antropológicos, sociológicos, jurídicos e políticos será retratado em sua acepção técnico-jurídica, não exatamente por ser o conceito mais adequado, mas para delimitar o campo investigativo.

Quer dizer, então, que esse substantivo abstrato reporta exatamente à fonte primária de emanação de todo o poder soberano, nos termos do parágrafo único do artigo primeiro da Constituição da República Federativa do Brasil de 1988 (CRFB/88), que se manifesta diretamente ou por intermédio de representação. Além disso, estabelece o desenho institucional do judiciário brasileiro nos artigos 96 ao 126, CRFB/88, cujas tensões serão analisadas no quarto tópico.

Percebe-se, pois, que num primeiro momento a dimensão formal de constituição será contrastada com sua dimensão material. Em linhas gerais, essas são algumas das premissas assumidas ao se discorrer sobre a temática das articulações entre povo, constituição e instituições judiciais.

Algumas dificuldades são identificadas quando se leva em consideração que os modernos, porém tradicionais, constitucionalismos estadunidense e europeu produziram uma elevada expectativa que ainda hoje não foi concretizada: a efetiva inclusão do povo nas decisões fundamentais da vida em sociedade. Com essa afirmação não se desconsidera os avanços humanos e políticos acarretados pela positivação dos direitos e das garantias fundamentais, bem como das garantias institucionais.

Contudo, estes discursos jurídico-político precisam estar vinculados às práticas sociais e institucionais, sob pena de menoscabar lutas sociais históricas num apanhado de construções teóricas abstratas (filosóficas, políticas e jurídicas), considerando o lado ocidental do mundo. Dito de outro modo, determinadas teorias exigem a elaboração de caminhos complementares para sua realização.

Inclusive, há dificuldades de aplicação prática de uma amálgama de vontades conflitantes, contrárias e contraditórias, entre si. Guardadas as proporções, equivalente aquilo que Rousseau, em seu contrato social, chamou de vontade geral (volonté générale) ou, anterior a 
isto, quando as revolucionárias e os revolucionários estadunidenses manifestavam diretamente e em nome próprio suas vontades de igualdade e de liberdade materializadas em: nós o povo (we the people) ${ }^{6}$.

As respostas sociais ou populares possuem facetas de muitas nuances, que devem ser comparadas com aquilo que se está em jogo: a dificuldade de deliberação nos múltiplos espaços públicos. Dentre estes espaços, sublinha-se o judicial, muitas das vezes marcado por um individualismo metodológico ou por um solipsismo judicial, ${ }^{7}$ ilustrado pela ausência de participações sociais nas deliberações judiciais, mas também pelas participações meramente formais.

É nessa tônica que cabe acrescentar os perigos que a "populisprudência" 8 constitui na atualidade, ou seja, algo que se reveste da forma de decisão judicial, mas, na verdade, não passa de uma opinião populista judicial. Em determinadas circunstâncias, mascaram comportamentos autocráticos. Fica o registro que isto representa, nada mais nada menos, que mais uma faceta de exclusão da participação do povo.

Além disso, denunciar os equívocos, embora importante, não satisfaz o problema. Faz-se, portanto, a opção de analisar a capacidade de a opinião popular afetar e de ser afetada pelas instituições judiciais. Do contrário, implica arcar com os custos reputacionais (credibilidade) das instituições e das pessoas que nestas desempenham suas funções.

Direto ao ponto, significa considerar os padrões sociais e extrajudiciais de controle do Judiciário permeados pela mudança de cultura jurídica, já que, no mais das vezes, os órgãos internos de controle (endógenos) não realizam essa tarefa à contento. A proposta consiste, em um só tempo, do controle social permeado pela legitimidade democrática, um campo a ser explorado com a contribuição inicial desse artigo.

Para traçar um paralelo com a situação acima indicada, deve-se levar em consideração que paradoxalmente o povo poderá ostentar visões irreconhecíveis com a própria constituição, "basta observar os resultados das pesquisas acerca da aceitação social da pena de morte no Brasil para se descobrir que a vontade da maioria pode estar em contraposição com a pretensa vontade coletiva". ${ }^{9}$ Todavia, o enredo que se assume é que as atuações do Judiciário não estão inócuas em relação às participações sociais.

Com "A promulgação de uma constituição democrática", a exemplo da CRFB/88, "permitiu que a oposição entre lei e direito fosse relida como a tensão entre as leis e a constituição, que passou a ser o núcleo em torno do qual se aglutinaram os discursos jurídicos ligados à justiça e à legitimidade".${ }^{10}$ Essa constatação pode ser entendida de pelo menos dois modos.

\footnotetext{
${ }^{6}$ Cf. ACKERMAN, Bruce. We the people: foundations. Harvard: Harvard University Press, 1991, v. 1.

${ }^{7}$ Cf. MADEIRA, Dhenis Cruz. O que é solipsismo judicial?. Revista Jurídica da Presidência, Brasília v. 22 n. 126 , fev./maio 2020, p. 191-210.

${ }^{8}$ Expressão utilizada por Conrado Hübner Mendes na conferência intitulada "A liberdade de expressão judicial" proferida em 04/12/2018, sessão noturna, no Encontro Preparatório para o IV Congresso Internacional de Direito Constitucional e Filosofia Política - As obrigações morais dos juízes, realizado na Universidade Federal de Minas Gerias (UFMG), Belo Horizonte/MG.

${ }^{9}$ COELHO, Inocêncio Mártires; COSTA, Alexandre Araújo. Teoria dialética do direito: a filosofia jurídica de Roberto Lyra Filho. Brasília: Faculdade de direito - UnB, 2017, p. 56.

10 COELHO, Inocêncio Mártires; COSTA, Alexandre Araújo. Teoria dialética do direito: a filosofia jurídica de Roberto Lyra Filho. Brasília: Faculdade de direito - UnB, 2017, p. 18.
} 
Primeiro, o texto legislado de uma constituição agora faz as vezes daquilo que fora o fetiche da lei positiva para a ideologia jurídica prevalente no século XIX, leia-se as diversas versões do positivismo jurídico, porém em um grau mais elevado de sofisticação. Sob as ideias de unidade da constituição, supremacia normativa, dentre outras ideias da mesma espécie, tem-se que o texto constitucional conteria todas as fórmulas de "solução" para as controvérsias da vida em sociedade. Ledo engano.

Num segundo entendimento, este mais crível, estaria que o texto constitucional, pelo menos na maioria dos países ocidentais, seria o ponto de abertura hermenêutica ou interpretativa e, de tal modo, o texto positivo da constituição passa a ser objeto de permanentes disputas argumentativas para o preenchimento dos possíveis sentidos e alcances de suas disposições normativas.

Aqui, a jurisdição constitucional assume um papel relevante em torno dessas questões, sobretudo quando se consideram as novas formas de expectativas criadas pelas práticas institucionais. Fala-se acerca das recorrentes ideias de supremacia judicial ou da teoria da "última palavra" sobre os sentidos da constituição pelo Judiciário. Por certo, críticas precisam ser levantadas para contrapor a prevalência do "caráter estatocêntrico das teorias modernas sobre o direito". ${ }^{11}$ Todavia, trata-se de uma forma de resistência que ainda se apresenta temerária e debilitada comparativamente à crença depositada no Judiciário.

Portanto, o povo, enquanto ator coletivo da história constitucional, demarcado por um conjunto de práticas, cujo tema será retomado mais à frente, oferece ou deveria oferecer uma "normatividade extraestatal",12 para a compreensão do fenômeno das participações sociais dentro das balizas do Estado democrático de direito. Ideais democráticos não se realizam apenas pela imposição das vontades majoritárias, nem ao arrepio destas. Resta analisar as tensões provocadas pela articulação dessas ideias, nos próximos tópicos.

\section{AINDA HÁ JUÍZES EM BERLIM, MAS TAMBÉM EXISTE O POVO}

Infere-se que parcela das formas do constitucionalismo contemporâneo perpassam pela crítica propositiva ao "juriscentrismo", isto é, a percepção de que os sentidos e os alcances da constituição não devem ser realizados exclusivamente por órgãos judiciais. De outro modo, esta é uma ideia em torno da qual se possa considerar como uma tarefa endereçada ao conjunto formado pelo povo e pelas instituições políticas e jurídicas.

Assim, cumpre nesse momento apresentar a motivação inicial para o título deste tópico. O moleiro de Sans-souci de François Andriex é citado com relativa regularidade em trabalhos acadêmicos, ${ }^{13}$ uma referência produzida em língua portuguesa, na década de 1980, serve para ilustrar sua ideia central:

${ }^{11}$ COELHO, Inocêncio Mártires; COSTA, Alexandre Araújo. Teoria dialética do direito: a filosofia jurídica de Roberto Lyra Filho. Brasília: Faculdade de direito - UnB, 2017, p. 46.

12 COELHO, Inocêncio Mártires; COSTA, Alexandre Araújo. Teoria dialética do direito: a filosofia jurídica de Roberto Lyra Filho. Brasília: Faculdade de direito - UnB, 2017, p. 18.

${ }^{13}$ CARVALHO, Claudio Oliveira de; MACEDO JÚNIOR, Gilson Santiago. Ainda há juízes em Berlim?. Justificando mentes inquietas pensam direito. São Paulo, [n.p.], 10 jan. 2017; STRECK, Lenio. Direito e literatura. O moleiro de Sans Souci, de François Andrieux. YouTube, 20 de setembro de 2013; ROCHA, João Batista de Oliveira. O controle 
Nas vizinhanças do Palácio Real de Sanssouci [sic], em Postdam, diz a tradição, havia um moinho de vento, cujo ruído incomodava o rei. Este exigiu que se paralisasse o moinho, com o que não concordou seu dono. Tendo, então, o rei ameaçado tomar violentamente o moinho, respondeu-Ihe o moleiro: "Sim, se não houvesse o Tribunal em Berlim". Tratava-se do famoso "Kammergericht" berlinense. ${ }^{14}$

Ao tomá-lo como ponto de partida, admitindo variações na forma e nas motivações que levaram o monarca a desistir da aquisição do moinho e o moleiro a resistir a essa pretensão autoritária, observa-se que, metaforicamente, esse poema simboliza a defesa de um Judiciário independente e imparcial. Por outras palavras, capaz de realizar a justiça no caso concreto sem considerar a posição política, social e econômica das partes envolvidas em eventual litígio, conferindo tratamento isonômico dos sujeitos processuais.

Segundo noticiam, o poeta e advogado francês retratava em suas linhas poéticas um "déspota esclarecido", Frederico II, Rei da Prússia, que em meados do século XVIII foi constrangido por um simples súdito. Apoiado na credibilidade do Judiciário da época, esse ato pode ser interpretado em pelo menos três sentidos, quais sejam: (i) a autocontenção do monarca; (ii) o controle popular dos atos dos governantes; (iii) a confiança na imparcialidade judicial.

O primeiro sentido apresentado contrapõe-se com o início da narrativa, pois com o objetivo de ampliar uma das alas do palácio real, ou incomodado com o barulho do moinho, conforme narrado acima, pretendeu-se inicialmente adquirir-lhe onerosamente a propriedade imóvel. Houve, contudo, recusa por parte do moleiro, daí surge o ato intimidatório, cujo desfecho já se tem conhecimento.

Interessa, num segundo momento, abordar a resposta apresentada pelo cidadão em face da ameaça real de expropriação de seu moinho, ou seja, o fato de invocar a tutela judicial na defesa de seus interesses face aos caprichos imperiais mostrou-se bastante e suficiente para que o rei num contra movimento desistisse de tal intento. Uma hipótese bastante contra fática e contra intuitiva.

O segundo sentido a ser abordado, controle popular dos atos dos governantes, é pouco explorado. Vale registrar que o momento histórico e cultural narrado no poema são significativos para "justificarem" a resposta apresentada pelo moleiro. Por certo, em outras versões do mesmo poema as razões apresentadas pelo cidadão são de ordem tradicional e de perpetuação da propriedade privada.

\footnotetext{
da constitucionalidade das leis na República Federal da Alemanha e no Brasil: um estudo de direito constitucional comparado. Revista de Informação Legislativa, Brasília, ano 17, n. 66, abr./jun. 1980, p. 75-98; entre outros.

${ }^{14}$ ROCHA, João Batista de Oliveira. O controle da constitucionalidade das leis na República Federal da Alemanha e no Brasil: um estudo de direito constitucional comparado. Revista de Informação Legislativa, Brasília, ano 17, n. 66 , abr./jun. 1980, p. 80.
} 
Para alguns, "O moleiro, em sua humildade, conta que o pai do seu pai, o seu pai e ele haviam trabalhado durante toda a vida naquele moinho e que seu filho também trabalharia quando mais velho" ${ }^{15}$ Seguramente, não se pode cogitar uma genuína reação social e política em face dos desmandos daquele que exerce o poder, mas numa reação individual que, por via oblíqua, produziu esse resultado.

Em termos de eficácia, os resultados obtidos pela disputa argumentativa desenvolvida entre o soberano e o populacho foi coincidente com o resultado da ação prática que culminou na manutenção do moinho. Sem embargo, pode-se prospectar que ao menos em termos simbólicos o poema é um singelo exemplo de controle social sobre os atos dos governantes, quer dizer, a possibilidade da efetiva participação na formação da "vontade estatal" e quiçá de controlar os atos daquelas e daqueles que lidam com a coisa pública realizado por toda a sociedade civil de maneira difusa (individual e coletivamente).

Já o terceiro e último sentido apontado que se interpreta do poema, a confiança na imparcialidade judicial, é o ponto mais conflitante e, sobre o qual será dedicada especial atenção. A atitude do moleiro está amparada por uma tradição cultural que permeia o campo de visão das instituições do Judiciário, isto porque o "judiciário, está livre de pressões e interesses políticos de qualquer ordem". ${ }^{16}$

Há, porém, outros elementos que sustentam algumas conclusões. Em certo sentido, o poema é corolário de um constrangimento criado ou reforçado pela teoria da "separação dos poderes" e da formação do Estado de direito. Identifica-se aqui uma relação paradoxal. Num primeiro plano, destoa de uma tradição francesa de aguda desconfiança em relação ao Judiciário, a exemplo do Barão de Montesquieu que considerava um poder nulo. ${ }^{17}$ No mesmo sentido, Edouard Lambert ao introduzir contundentes críticas à ação mais proeminente de determinados juízes ou simplesmente à "aristocracia judicial estadunidense". ${ }^{18}$

Diante desse quadro, resta verificar se e em que medida as ideias até agora trabalhadas estão presentes na experiência brasileira. Cuida-se, portanto, de agora em diante, analisar como seria uma possível resposta de um juiz brasileiro a eventual demanda apresentada por um "moleiro brasileiro" em defesa de seu "moinho"; ato contínuo, expõe-se algumas implicações teóricas acerca das participações sociais na construção dos sentidos e alcances da constituição.

\footnotetext{
${ }^{15}$ CARVALHO, Claudio Oliveira de; MACEDO JÚNIOR, Gilson Santiago. Ainda há juízes em Berlim?. Justificando mentes inquietas pensam direito. São Paulo, [n.p.], 10 jan. 2017.

${ }^{16}$ ROCHA, João Batista de Oliveira. O controle da constitucionalidade das leis na República Federal da Alemanha e no Brasil: um estudo de direito constitucional comparado. Revista de Informação Legislativa, Brasília, ano 17, n. 66, abr./jun. 1980, p. 80.

17 No original: "Les lois qui établissent le droit de suffrage sont donc fondamentales dans ce gouvernement." MONTESQUIEU. L'esprit des lois. Edition Edouard Laboulaye. Paris: Garnier Frères, 1875, p. 330 (CEuvres completes) [Livre deuxième, Chapitre II].

${ }^{18}$ No original: "I'aristocratie judiciaire américaine". LAMBERT, Edouard. Le gouvernement des juges et la lutte contre la législation sociale aux États-Unis: la expérience américaine du controle judiciaire de la constitutionnalité des lois. 5. ed. Paris : Marciel Giard \& Cie, 1921, p. 124.
} 


\section{ENQUANTO ISSO... UMA VERSÃO ABRASILEIRADA}

Para satisfazer os fins pretendidos nesse artigo, um exemplo teórico será suficiente para explorar as dimensões de significado pretendidas, sem, contudo, exaurir o tema. Antes, porém, cabe considerar que existem pelo menos duas maneiras para estabelecer as relações entre o público e o privado: de um lado, tem-se fenômenos como o patrimonialismo e o coronelismo, isso é, um "sistema que entrelaça poder privado dos ditos coronéis ao poder público, excluindo, dessa barganha, a grande massa da população bem como seus interesses", 19 fatores que explicam, em parte, a prevalência dos interesses privados, de outro lado, a prevalente ideia de "supremacia" do interesse público. Esse artigo, analisa reflexos dessa última modalidade.

Nas linhas que restam será realizada uma espécie de releitura do moleiro de Sanssouci, com o devido cuidado para não se realizar uma caricatura da identidade brasileira como "naturalmente" inferior aos modelos estrangeiros. ${ }^{20}$ Os resultados desenhados são distintos dos apresentados originalmente, porque os elementos que serão adicionados são radicalmente distintos.

Ao refazer o percurso do moleiro prussiano aos moldes brasileiros atribuirá maior ênfase aos aspectos técnicos-jurídicos em detrimento dos aspectos poéticos. Fato que, já se reconhece de antemão, diminui o encanto do poema apresentado. Para contextualizar alguns elementos serão substituídos.

Em uma localidade brasileira qualquer, num ambiente campestre, ao contrário de uma conversa com o monarca, a proposta de aquisição originária da propriedade imóvel particular se manifesta por meio de um decreto de desapropriação fundado em utilidade pública. Diferentemente do primeiro moleiro, o brasileiro vê-se obrigado a oferecer resposta (contestação) à ação de desapropriação proposta pelo ente público em seu desfavor (União, Estados, Municípios, Distrito Federal e Territórios), ${ }^{21}$ regida pelo Decreto-Lei n. 3.365, de 21 de junho de 1941.

O referido decreto dispõe sobre desapropriações por utilidade pública e foi decretado por Getúlio Vargas e, nos termos do art. 2º, determina que "mediante declaração de utilidade pública, todos os bens poderão ser desapropriados". E, isso certamente inclui o moinho do moleiro brasileiro. No outro lado do poema à brasileira, com certeza figurará o "Presidente da República, Governador, Interventor ou Prefeito", como autoridade competente para declarar a utilidade pública do bem, mediante publicação de decreto (ato administrativo), conforme dispõe o art. 6ㅇ do Decreto-Lei supramencionado.

\footnotetext{
${ }^{19}$ ALMEIDA, Silvio; FALEIROS, Juliana Leme. O coronelismo de Victor Nunes Leal e a modernização conservadora: colocações iniciais. Revista de Direito, Viçosa, v. 12, n. 01, 2020, p. 22.

20 Cf. VIANNA, Oliveira. Instituições políticas brasileiras. Brasília: Senado Federal, 1999 (Biblioteca básica brasileira).

21 O artigo terceiro do Decreto-Lei também admite que "concessionários de serviços públicos e os estabelecimentos de carater (sic) público ou que exerçam funções delegadas de poder público poderão promover desapropriações mediante autorização expressa, constante de lei ou contrato".
} 
Alterando o que tem de alterado, qualquer dessas autoridades ou até mesmo determinadas autarquias sob regime especial ${ }^{22}$ figurariam o papel do Rei Frederico II. As hipóteses de utilidade pública listadas em rol exemplificativo no art. 5 do Decreto-Lei possuem elevado grau de abstração e envolvem expressões cujo conteúdo é indeterminado, tais como: "segurança nacional", "defesa do Estado", "salubridade pública", "construção de edifícios públicos, monumentos comemorativos e cemitérios", entre outras circunstâncias que autorizam a desapropriação.

Oposto ao monarca que se autoconteve ou foi contido e não avançou sobre a propriedade privada do moleiro sob a constatação de que "ainda há juízes em Berlim", o Chefe do Executivo expropriante (sic), no exemplo brasileiro, não só alegou urgência e depositou a quantia arbitrada, como também foi imitido provisoriamente na posse do bem imóvel pelo juiz, em conformidade com o art. 15 do Decreto-Lei n. 3.365/1941.

Aquilo que é preciso para desenvolver o exemplo e resgatar a "rede de proteção jurídica e política" das magistradas e dos magistrados brasileiros, mencionada na parte introdutória desse artigo, é requisito de validade dos atos processuais praticados, isto é, apenas as juízas e os juízes que "tiverem garantia de vitaliciedade, inamovibilidade e irredutibilidade de vencimentos poderão conhecer dos processos de desapropriação", conforme positivado no caput do art. 12, do referido Decreto-Lei.

Ainda por cima, que a contestação apresentada pelo moleiro brasileiro somente "poderá versar sobre vício do processo judicial ou impugnação do preço; qualquer outra questão deverá ser decidida por ação direta", conforme preceitua o art. 20 do Decreto-Lei. Por certo, essas prerrogativas asseguradas ao Estado brasileiro, aplicáveis mesmo no caso de apossamento administrativo, desapropriação direta realizada pelo ente público sem a observância das disposições acima referidas, desencorajam as moleiras e moleiros brasileiros e, por vezes, faz com que a versão brasileira desse poema não apresente um desfecho tão interessante quanto o original.

É válido mencionar que ressalvadas hipóteses excepcionalíssimas o bem será consolidado ao patrimônio do ente responsável pela desapropriação, resolvendo-se a demanda judicial na fixação (majoração ou confirmação) do valor da indenização (quantum indenizatório). Ou seja, no caso brasileiro, o moleiro irremediavelmente perderá seu moinho, assegurado o direito fundamental à indenização.

Resta patente que o direito de petição, por si só, não será capaz de assegurar outros direitos a exemplo do direito à propriedade privada. Sob outro ângulo, não é possível aproximar, de modo idêntico, esse exemplo brasileiro ao poema, mas a intenção ficou concentrada apenas em demonstrar que o ordenamento jurídico brasileiro assegura a pretensão estatal, mas deixa à cargo da discricionariedade da administração pública a função de assegurar a utilidade pública e a urgência, diante da situação concreta, na realização do "bem comum" e do "interesse público", em seu sentido primário.

Disposições normativas que podem perfeitamente ser deturpadas, pois, conforme já se disse, são conceitos jurídicos de ampla abertura semântica. Esse tensionamento traz à tona

\footnotetext{
${ }^{22}$ À exemplo da Agência Nacional de Energia Elétrica (ANEEL), uma autarquia em regime especial diretamente vinculada ao Ministério de Minas e Energia, que nos termos do art. 10 da Lei n. 9.074/1995 possui competência para declarar utilidade pública.
} 
a noção e a compreensão do direito enquanto proteção dos direitos e das garantias fundamentais, da controversa atuação judicial contramajoritária ${ }^{23}$ ao mesmo tempo em que assegura os direitos difusos e coletivos.

Sendo o direito um espaço de lutas, à medida que se coloca as pretensões e resistências das partes litigantes diante de um terceiro imparcial (Estado-juiz), é que as moleiras e os moleiros brasileiros poderiam ficar tranquilos, porque "ainda há juízes em Berlim". Entretanto, quando se questiona quem são as juízas e os juízes de Berlim, no caso brasileiro, chegase a algumas constatações que precisam ser refletidas.

Recentemente, o Conselho Nacional de Justiça (CNJ) divulgou o Perfil sociodemográfico dos magistrados brasileiros 2018. Os dados apresentados revelam que "As mulheres representam $38 \%$ da magistratura", "A maior parte dos magistrados (80\%) é casada ou possui união estável" sendo que "a maioria se declara branca (80,3\%)". ${ }^{24}$ Além disso, " $51 \%$ deles têm o pai com ensino superior completo ou mais, e $42 \%$ com a mãe na mesma faixa de escolaridade", o perfil religioso da magistratura aponta que "o catolicismo a religião mais frequente $(57,5 \%)$ ". ${ }^{25}$ O perfil apresenta ainda que apenas " $05 \%$ dos magistrados brasileiros têm o título de doutor, $16 \%$ de mestre" ${ }^{26}$

Conforme dados do CNJ, "Menos de 01\% dos magistrados em atividade declarou ter ingressado na magistratura por meio de reserva de vagas" numericamente constituem um universo de 54 (cinquenta e quatro) magistrados, destes 30 (trinta) preencheram as vagas reservadas as pessoas portadoras de deficiência e 24 (vinte e quatro) destinadas às pessoas negras (pretas ou pardas). ${ }^{27}$ Acrescenta-se, ainda, que a metodologia empregada pela pesquisa do CNJ foi de aplicação de questionários às magistradas e aos magistrados brasileiros de forma facultativa, cujo espaço amostral "contou com a participação de 11.348 de um total de 18.168 magistrados ativos, um índice de resposta de 62,5\%". ${ }^{28}$

A bem da verdade, fica o registro que em 2015 o Conselho Nacional do Ministério Público (CNMP) publicou pesquisa pioneira que revelou resultados semelhantes. Essas informações foram analisadas sobre o sugestivo título: Ministério Público: guardião da democracia brasileira? ${ }^{29} \mathrm{cuja}$ ironia consiste no fato de que o Ministério Público "está longe de produzir os efeitos anunciados no título de 'guardião da democracia'". ${ }^{30}$

\footnotetext{
${ }^{23}$ Cf. CADÓ, Rafaela Oliveira Reis; MOTA, Fabiana Dantas Soares Alves da. A importância da função contramajoritária do STF frente a atual sociedade plural. Revista de Filosofia do Direito, do Estado e da Sociedade, Natal, v. 09, n. 02, jul./dez. 2018, p. 23-36. Em sentido contrário, Cf. NUNES, Daniel Capecchi. A imaginação constitucional brasileira e o mito da atuação contramajoritária: conferências nacionais de políticas públicas e a concretização de direitos de minorias por Poderes eleitos. Revista Publicum, Rio de Janeiro, v. 05, n. 01, 2019, p. 167-191.

${ }^{24}$ BRASIL. Conselho Nacional de Justiça. Perfil sociodemográfico dos magistrados brasileiros 2018. Brasília, 2018, p. 08.

${ }^{25}$ BRASIL. Conselho Nacional de Justiça. Perfil sociodemográfico dos magistrados brasileiros 2018. Brasília, 2018, p. 15.

${ }^{26}$ BRASIL. Conselho Nacional de Justiça. Perfil sociodemográfico dos magistrados brasileiros 2018. Brasília, 2018, p. 21.

${ }^{27}$ BRASIL. Conselho Nacional de Justiça. Perfil sociodemográfico dos magistrados brasileiros 2018. Brasília, 2018, p. 26.

${ }^{28}$ BRASIL. Conselho Nacional de Justiça. Perfil sociodemográfico dos magistrados brasileiros 2018. Brasília, 2018, p. 05.

${ }^{29}$ Cf. DUARTE, Thais et. al. Ministério Público: guardião da democracia brasileira?. Rio de Janeiro: CESEC, 2016.

${ }^{30}$ DUARTE, Thais et. al. Ministério Público: guardião da democracia brasileira?. Rio de Janeiro: CESEC, 2016, p. 07.
} 
O conteúdo da pesquisa do CNMP revela que 76\% dos Promotores e Procuradores são brancos, 70 \% são homens, 31,2 \% possuem 50 anos ou mais e $45 \%$ ingressaram entre 1988 e 1998. Semelhante ao perfil do Judiciário brasileiro - "burocrático, moroso e pouco permeável às demandas populares", ${ }^{31}$ existe uma sobrerrepresentação masculina e caucasiana no Ministério Público, cujos membros "compõem um segmento fortemente elitizado - na maioria, homens brancos, oriundos das classes média e alta". ${ }^{32}$

Diante dessas considerações pode-se inferir que ainda há juízas e juízes em Berlim, mas algumas e alguns se comportam como se não o povo não existisse. Diante disso, não se supõe que a generalização da desconfiança do povo em relação ao Judiciário seria uma solução plausível, de outra sorte, há que se ir às raízes do problema, no sentido filosófico do termo, radicalizar a constituição.

Uma teoria crítica do direito no Brasil aponta para a necessidade de inserir as participações do povo nas discussões atinentes aos conteúdos semânticos e pragmáticos da constituição. Esse processo deve se realizar de tal forma que seja capaz de fazer frente às instituições, jurídicas e políticas, que arrogam para si, cada qual ao seu modo, as prerrogativas de interpretar o texto constitucional. E, com Hans-Georg Gadamer se sabe que não há como separar interpretação de aplicação. ${ }^{33}$

Logo, diante desse impasse, sugere-se inicialmente a abertura para que o povo possa diretamente defender seus "moinhos" ou suas interpretações parciais sobre os significados atribuídos aquilo que chamam de "moinho" (constituição). E, dessa maneira fazer frente aos desmandos daqueles e daquelas que se atribuem "soberanas e soberanos".

\section{TENSÕES ENTRE CONSTITUCIONALISMO E DEMOCRACIA: UMA RESPOSTA OFERECIDA PELA CONSTITUIÇÃO RADICAL}

No momento em que se fala sobre o conteúdo de temas difíceis como é o caso do constitucionalismo, da democracia e da constituição radical é necessário considerar que "as complexas sociedades pluralistas se afastam da concepção de uma Estado-nação fundado numa população relativamente homogênea". ${ }^{34}$ Assim, o dissenso enquanto possibilidade efetiva de manifestar discordância está no epicentro do Estado democrático de direito.

Sem dúvidas, não constitui escopo, nem poderia ousar tamanha pretensão, desse artigo esgotar os significados possíveis para expressões demasiadamente amplas. Mesmo porque, "em termos rigorosos, não há um constitucionalismo, mas vários constitucionalismos". ${ }^{35}$ Para conferir o mínimo de sustentação a esse tópico derradeiro, entende-se por constitucio-

\footnotetext{
31 lbid., p. 51.

32 Ibid., p. 64.

${ }^{33}$ Cf. GADAMER, Hans-Georg. Verdade e método I: traços fundamentais de uma hermenêutica filosófica. Tradução de Flávio Paulo Meurer e Enio Paulo Giachini. 15. ed. Petrópolis: Vozes, 2015, v. 1 (Pensamento humano).

${ }^{34}$ ÁVILA, Luiz Augusto Lima de. Tópica e jurisprudência no direito comunitário: uma investigação dos fundamentos jurídico-científicos para a hermenêutica e a fundamentação da obrigatoriedade do direito. Belo Horizonte: FUMARC, 2013, p. 51.

${ }^{35}$ CANOTILHO, José Joaquim Gomes. Direito constitucional e teoria da constituição. 2. ed., Coimbra: Almedina, 1998, p. 51.
} 
nalismo como o movimento filosófico, político e jurídico, surgido com o advento da modernidade ocidental, de inspiração liberal, que buscou limitar a atuação estatal pelo reconhecimento dos direitos e das garantias fundamentais contidos numa constituição.

O substantivo democracia alberga, entre outros significados, a possibilidade efetiva das participações do povo nas decisões da vida em sociedade. ${ }^{36} \mathrm{Um}$ complexo de relações que contempla a escolha direta dos governantes, por meio de eleições periódicas e universais, a participação direta e indireta na condução da agenda pública, a gestão da coisa pública de forma escorreita, a efetiva participação social, o reconhecimento e a proteção dos grupos vulneráveis, entre outros atributos.

Existe, contudo, tensões entre o constitucionalismo e a democracia, representada especialmente quanto as questões controversas que, por um lado, preveem a limitação do Estado e inclusive dos particulares pelo direito. Por outro lado, a regra da maioria é o padrão operativo dos sistemas democráticos, isso não equivale a dizer que sempre as vontades majoritárias devem prevalecer. $\mathrm{O}$ tradicional exemplo com o qual se ilustra parcela expressiva dessas tensões é o controle judicial de constitucionalidade.

Basta lembrar o clássico dilema no qual as magistradas e magistrados que não foram avaliadas ou avaliados pelo escrutínio público (voto popular, direto, secreto e virtualmente universal) podem anular leis promulgadas por um complexo sistema legislativo que, via de regra, envolve um número expressivo de congressistas e outras autoridades. Há também a possibilidade de outras espécies normativas como emendas constitucionais, atos normativos, leis estaduais, distritais e municipais, entre outros exemplos possíveis sejam submetidas ao controle judicial.

Em grossas linhas, esses são os principais argumentos que norteiam uma falaciosa disputa entre o Judiciário e o Parlamento pela supremacia interpretativa da constituição. Apesar de haver argumentos relevantes para ambos lados, por razões de tempo e de espaço não serão trabalhadas aqui. Conforme já se afirmou, a tônica desse artigo repousa sobre outro aspecto, ainda pouco explorado, que é a desconstrução dos órgãos estatais como referência absoluta para a interpretação do texto constitucional indica os traços necessários para uma "sociedade radicalmente democrática", ${ }^{37}$ campo sobe o qual serão direcionados os olhares.

Os estudos desenvolvidos nesse tópico procuram de forma crítica pensar e repensar os fundamentos do controle de constitucionalidade diante dos aportes teóricos de uma constituição radical, que "não sintetiza a tensão entre poder constituinte (democracia) e poderes constituídos: ela é precisamente isso, a tensão!". ${ }^{38} 0$ tema de análise proposto compõe-se, portanto, da conflituosa interação estatal e social e das possibilidades de manifestações de um controle social difuso aplicável as instituições judiciais como uma das possíveis respostas para se determinar o papel desempenhado pela sociedade civil nesse cenário.

Ao se trabalhar com a categoria estabelecida não se pretende apresentar uma "solução pronta" capaz de resolver um problema talvez insolúvel. De todo modo, ao se tecer considerações críticas sobre a constituição em seu sentido radical, tem-se que a existência de um

\footnotetext{
${ }^{36}$ Cf. DAHL, Robert Alan. Polyarchy: participation and opposition. Yale: Yale University Press, 1971.

${ }^{37}$ CHUEIRI, Vera Karam de. Constituição radical: uma ideia uma prática. Revista da Faculdade de Direito (UFPR), Curitiba, n. 58, 2013, p. 32.

IIbid., p. 29.
} 
controle "sem controles" malfere o Estado democrático de direito. Nesse sentido, as instituições estatais as quais se atribui o título de democráticas possuem, na largada, o dever de prestação de conta argumentativa das decisões adotadas.

Num primeiro momento, importa menos o sentido da decisão judicial prolatada, sempre mais relevante será o dever de explicitar as razões que a suportam. É certo, que remete ao dever de justificação pública e argumentativa. Isto porque, as decisões que afetam, direta ou indiretamente a coletividade e, assim apresentam repercussões na esfera pública precisam de substanciosa fundamentação jurídica, política e social sob pena de arbitrariedade.

Não se trata apenas de uma variável externa de identificação do problema, mas conforme restou demonstrado a legitimidade do Judiciário deriva, em parte, da credibilidade que suas instituições desfrutam. Às vezes é necessário recorrer a mecanismos de controle individual das decisões tomadas pelas autoridades competentes de modo que aquelas estejam ancoradas na forma de exercício da autoridade institucional na qual fazem parte, isso também se aplica as magistradas e aos magistrados.

Igualmente os fundamentos de uma decisão judicial devem prestar relevantes serviços à autoridade do órgão prolator de modo a justificarem para a parte sucumbente os porquês daquela decisão. Também, deve-se uma satisfação para a sociedade civil de maneira geral, ao demonstrar as razões pelas quais determinada lei ou ato normativo afronta a constituição e, portanto, deve ser declarada nula.

O encaminhamento final dos argumentos aponta para a inserção nas instâncias decisórias do poder de codecisão. Implica considerar os traços comunitários presentes no ator coletivo povo, não como tentativa de apropriação instrumental ou argumentativa das lutas e das conquistas e sociais. Menos ainda, pela redução de elementos plurais e históricos a uma experiência particular e efêmera. Pois, no momento em que o povo se manifesta, a participação, enquanto um processo democrático que não se esgota em si mesma, somada ao não silêncio da sociedade civil é revelador para a identificação de um estado de coisas que se pretende construir.

\section{- CONCLUSÃO}

Em resposta à problematização assentada na parte introdutória desse artigo apresenta-se, diante do questionamento sobre a existência de juízas e juízes automaticamente os interesses individuais estariam resguardados confirma-se a resposta negativa. Isto é, há alguns aspectos de ordem normativa e de composição institucional do Judiciário brasileiro que inviabilizam a proteção judicial de determinados interesses.

Por outro lado, a ideia fluída de democracia carrega consigo diversos problemas. Especialmente no caso de o povo estar distanciado da constituição, isso, sem dúvidas, conduz as discussões para as instituições, enquanto forma de proteção das condições elementares de democracia. No entanto, essa constatação apenas redimensionou a questão ao invés de solucioná-la; assim, no final das contas, persistem as dúvidas sobre o que fazer se as instituições, em geral, e as instituições jurídicas, em particular, estiverem apartadas do povo. 
Esse artigo se posicionou favoravelmente a necessidade de participação efetiva (direta e indiretamente) do povo nas diversas instâncias decisórias da República Federativa do Brasil dentro das balizas do Estado democrático (constitucional) de direito. Viu-se o ordenamento jurídico brasileiro permite em certas circunstâncias que as "moleiras" e os "moleiros" sejam privados de seus moinhos. Além disso, a existência de juízas e juízes, no caso brasileiro, via de regra, é formada por extratos sociais, étnicos, de gênero e de filiação religiosa bastantes específicos (hegemônicos).

Conforme já se disse, essas evidências não justificam a completa desconfiança em reação ao Judiciário brasileiro, embora uma generosa dose de desconfiança seja salutar para o exercício da democracia; mas, de fato, o povo precisa participar das decisões fundamentais sobre a vida em sociedade. Com a superação da ideia de que as visões do povo são sempre conflitantes com a constituição, percebe-se que o "moinho" capaz de projetar um horizonte inclusivo de efetiva participação social será a própria Constituição Federal de 1988.

\section{REFERÊNCIAS}

ACKERMAN, Bruce. We the people: foundations. v. 1. Harvard: Harvard University Press, 1991.

ALMEIDA, Silvio; FALEIROS, Juliana Leme. O coronelismo de Victor Nunes Leal e a modernização conservadora: colocações iniciais. Revista de Direito, Viçosa, v. 12, n. 01, 2020, p. 01-26.

ANDRIEUX, François. Le meunier de Sans-souci [Anecdote]. Paris : Bibliothèque Numérique Wikisource, [s.d.] (Livre électronique).

ÁVILA, Luiz Augusto Lima de. Tópica e jurisprudência no direito comunitário: uma investigação dos fundamentos jurídico-científicos para a hermenêutica e a fundamentação da obrigatoriedade do direito. Belo Horizonte: FUMARC, 2013.

BRASIL. Conselho Nacional de Justiça. Perfil sociodemográfico dos magistrados brasileiros 2018. Brasília, 2018. Disponível em: http://www.cnj.jus.br. Acesso em: 05 dez. 2018.

CADÓ, Rafaela Oliveira Reis; MOTA, Fabiana Dantas Soares Alves da. A importância da função contramajoritária do STF frente a atual sociedade plural. Revista de Filosofia do Direito, do Estado e da Sociedade, Natal, v. 09, n. 02, jul./dez. 2018, p. 23-36.

CANOTILHO, José Joaquim Gomes. Direito constitucional e teoria da constituição. 2. ed., Coimbra: Almedina, 1998

CARVALHO, Claudio Oliveira de; MACEDO JúNIOR, Gilson Santiago. Ainda há juízes em Berlim?. Justificando - mentes inquietas pensam direito. São Paulo, [n.p.], 10 jan. 2017. Disponível em: http://www.justificando. Acesso em: 06 dez. 2018.

CHUEIRI, Vera Karam de. Constituição radical: uma ideia uma prática. Revista da Faculdade de Direito (UFPR), Curitiba, n. 58, 2013, p. 25-36.

COELHO, Inocêncio Mártires; COSTA, Alexandre Araújo. Teoria dialética do direito: a filosofia jurídica de Roberto Lyra Filho. Brasília: Faculdade de direito - UnB, 2017. 
DAHL, Robert Alan. Polyarchy: participation and opposition. Yale: Yale University Press, 1971. DUARTE, Thais; LEMGRUBER, Julita; MUSUMECI, Leonarda; RIBEIRO, Ludmila. Ministério Público: guardião da democracia brasileira?. Rio de Janeiro: CESEC, 2016.

GADAMER, Hans-Georg. Verdade e método I: traços fundamentais de uma hermenêutica filosófica. Tradução de Flávio Paulo Meurer e Enio Paulo Giachini. 15. ed. Petrópolis: Vozes, 2015, v. 1 (Pensamento humano).

LAMBERT, Edouard. Le gouvernement des juges et la lutte contre la législation sociale aux États-Unis : la expérience américaine du controle judiciaire de la constitutionnalité des lois. 5. ed. Paris : Marciel Giard \& Cie, 1921.

MADEIRA, Dhenis Cruz. O que é solipsismo judicial?. Revista Jurídica da Presidência, Brasília v. 22 n. 126, fev./maio 2020, p. 191-210.

MONTESQUIEU. L'esprit des lois. Edition Edouard Laboulaye. Paris : Garnier Frères, 1875 (CEuvres completes).

NUNES, Daniel Capecchi. A imaginação constitucional brasileira e o mito da atuação contramajoritária: conferências nacionais de políticas públicas e a concretização de direitos de minorias por Poderes eleitos. Revista Publicum, Rio de Janeiro, v. 05, n. 01, 2019, p. 167-191.

ROCHA, João Batista de Oliveira. O controle da constitucionalidade das leis na República Federal da Alemanha e no Brasil: um estudo de direito constitucional comparado. Revista de Informação Legislativa, Brasília, ano 17, n. 66, abr./jun. 1980, p. 75-98.

ROUSSEAU, Jean-Jacques. Du contrat social ou principes du droit politique. Paris : Union Générale d’Éditions, 1963.

SIEYÈS, Emmanuel Joseph. Qu'est-ce que le Tiers Etat?. Paris : Editions du Boucher, 2002.

STRECK, Lenio. Direito e literatura. O moleiro de Sans Souci, de François Andrieux. YouTube, 20 de setembro de 2013. Disponível em: https://www.youtube.com/watch?v=UaqSCsYh07o. Acesso em 10 dez. 2018.

VIANNA, Oliveira. Instituições políticas brasileiras. Brasília: Senado Federal, 1999 (Biblioteca básica brasileira). 